\title{
Book Review - Flexible Higher Education. Reflections from Expert Experience
}

\author{
Editor: Elizabeth J. Burge (2007). Flexible Higher Education. Reflections from Expert \\ Experience. London: The Society for Research into Higher Education \& Open University Press \\ (166 pages). ISBN - 13: 978-033521776-2.
}

Reviewer: Heather Kanuka, University of Alberta, Canada

'Flexible Higher Education' is an edited book with six of the chapters written by the book editor (Elizabeth Burge), followed by seven reflective chapters written by well-known distance educators and concludes with a final chapter, again written by the editor, Elizabeth Burge.

The contents of the book are based on the work of what the editor considers to be pioneers within the field of distance education, 44 in total. Funded by the Social Sciences and Humanities Research Committee, Burge interviewed each of these distance education pioneers. The composition of the pioneers selected is a good cross section of individuals from diverse geographies: Canada, Germany, Hong Kong, Oceania, United Kingdom, and United States. The kind of institutional experience of the participants selected by Burge is also varied: institutional leadership, institutional unit/ faculty/ departmental level administration, programme/ curricula development/ evaluation, teaching skill development, technology application, research/ documentation and development aid in various countries. The method used to collect the data was in the form of interviews, requesting the participants to reflect on their practice by exploring a range of topics: key challenges faced, guiding ideas, values, etc., for their practice; stressors experienced, lessons learning, technology managed; career highlights and lowlights; perceptions on any significant changes in distance education in their career; and factors that sustained their careers. The participants were also asked to offer advice to less experienced colleagues, as well as concerns for the future of distance education within higher education environments.

I personally found the first chapter by Burge to be difficult to read at times. Not because Burge's writing is poor. Indeed, Burge's writing is superb throughout the book. Rather, I found it was difficult in that I felt, as a reader, occasional statements were rather pejorative. For example, on page 7, Burge writes: "Postsecondary educators with shorter experiential views of distance and flexible learning may assume that lessons learned 25 years ago are not so relevant for today's context." While Burge may perceive this in her world, these kinds of statements in the first chapter are objectionable assumptions and generalizations to those individuals who are relatively new to distance education.

Once beyond the first chapter, the book becomes quite interesting. The following five chapters written by Burge are based on the analysis of the interviews. Nicely organized and based on an excellent analysis of the interviews, the reader is taken on a journey that moves from the challenges of inexperience, guiding practices, managing technology, learning from experience, 
Kanuka

and looking forward. Each of these chapters are broken down into relevant themes on each of the chapter topics, with carefully selected quotes by the participants, weaved together in a manner that brings the abstract to the practical.

The following seven reflective chapters were also interesting reads. Perhaps the most interesting aspect to the commentators' meta-reflections was the way each overlaid their own world views on the data presented. Specifically, with the exception of Michael Moore's chapter, the reflections tended to be more about the chapter authors' personal views of distance education, than reflections on the prior chapters written by Burge.

In conclusion, the data analysis chapters written by Burge were a wonderful read; reminiscent of a walk down memory lane or a fireside chat with many colleagues I've never met. I've tried to give an accurate and honest description of this book and would like to close by saying that for distance education practitioners, new or experienced, I'd highly recommend purchasing this book. 